\title{
O Ensino de Leitura em Bloomfield e na Análise do Comportamento*
}

\section{Reading Instruction in Bloomfield and Behavior Analysis \\ Enseñanza de la Lectura en Bloomfield y Análisis de la Conducta}

Djenane Brasil da Conceição', Maria de Lourdes R. F. Passos ${ }^{2}$, Júlio César C. de Rose ${ }^{3}$

Resumo: Leonard Bloomfield foi um dos mais importantes linguistas do século XX, era behaviorista e influenciou muitos aspectos da obra de B. F. Skinner. Na década de 1930, Bloomfield elaborou um método de ensino de leitura, culminando na publicação de "Let's Read," em 1961. O procedimento de ensino básico consiste em apresentar pares de palavras que contrastam em apenas uma ou algumas letras e no planejamento cuidadoso da apresentação das relações grafema-fonema regulares, semirregulares e irregulares nestas palavras. As concepções de leitura de Bloomfield e de Skinner são muito semelhantes e o método bloomfieldiano para seu ensino é compatível com os procedimentos de ensino utilizados em análise do comportamento. Ambos consideram que um repertório básico de leitura, a emissão das respostas verbais vocais correspondentes ao texto impresso, que Skinner chama de comportamento textual, é pré-requisito para a leitura com compreensão, e defendem a elaboração de métodos de ensino que promovam a aprendizagem sem erros. Este artigo consiste numa análise do método do ensino de leitura de Bloomfield, à luz da análise comportamental, e em uma comparação entre estas perspectivas. A adaptação do método à língua portuguesa e sua combinação com princípios e procedimentos de instrução programada têm grande potencial para participar da solução do problema dos altos índices de analfabetismo funcional no Brasil.

Palavras-chave: ensino de leitura, comportamento textual, aprendizagem sem erros, Bloomfield, Skinner 
Abstract: Leonard Bloomfield was one of the most important linguists of the twentieth century. He was a behaviorist, and influenced many aspects of B. F. Skinner's work. In the 1930s, Bloomfield developed a method for teaching reading, which culminated in the publication of "Let's Read" in 1961. His basic teaching procedure is to present pairs of words that contrast in just one or a few letters and to present regular, semi-regular and irregular grapheme-phoneme relations in those words. Bloomfield's and Skinner's concepts about reading are very similar and Bloomfield's method for teaching reading is also compatible with the teaching procedures used in behavior analysis. Both approaches consider that a basic repertoire of reading, the emission of vocal verbal responses corresponding to the printed text, called textual behavior by Skinner, is a prerequisite for reading with understanding. They advocate the development of teaching methods that promote errorless learning. This paper constitutes an analysis of Bloomfield's method for teaching reading in the light of behavior analysis, and a comparison of these perspectives. The adaptation of Bloomfield's method to the Portuguese language and its combination with principles and procedures of programmed instruction have great potential toward solving the problem of high rates of illiteracy in Brazil.

Keywords: teaching reading, textual behavior, errorless learning, Bloomfield, Skinner

Resumen: Leonard Bloomfield fue uno de los lingüistas más importantes del siglo XX, era conductista e influyó en muchos aspectos de la obra de B. F. Skinner. En la década de 1930, Bloomfield desarrolló un método de enseñanza de lectura que culminó con la publicación de "Let's Read," en el año 1961. El procedimiento básico de enseñanza es presentar pares de palabras que contrastan en tan sólo una o unas pocas letras y planificación cuidadosa de la presentación de relaciones grafema-fonema regulares, semirregulares e irregulares, en estas palabras. Los conceptos de lectura de Skinner y Bloomfield son muy similares y el método de Bloomfield para enseñar a leer es compatible con los procedimientos de enseñanza utilizados en el análisis del comportamiento. Ambos consideran que un repertorio básico de lectura, la emisión de respuestas verbales vocales que corresponde al texto impreso, lo que Skinner llama comportamiento textual, es un requisito previo para la lectura con comprensión y abogan por el desarrollo de métodos de enseñanza que promueven el aprendizaje sin errores. Este trabajo constituye un análisis del método de enseñanza de lectura de Bloomfield a la luz del análisis de la conducta, y una comparación de estas perspectivas. La adaptación del método a la lengua portuguesa y su combinación con los principios y procedimientos de instrucción programada tiene un gran potencial para participar en la solución del problema de las altas tasas de analfabetismo funcional en Brasil.

Palabras-clave: enseñanza de lectura, comportamiento textual, aprendizaje sin errores, Bloomfield, Skinner

${ }^{*}$ Nota dos autores: Agradecemos a leitura cuidadosa e as excelentes sugestões feitas pela Profa Dr ${ }^{\text {a }}$. Terezinha Bittencourt a uma versão anterior deste artigo. Agradecemos a revisão do texto em espanhol feita por Jaume Ferran Aran Cebria, mestrando do PPGPsi/UFSCar. A coautora Djenane B. da Conceição recebeu apoio financeiro dos programas Capes/Fulbright e Capes Prodoutoral para a pesquisa de que resulta este artigo. A preparação deste manuscrito contou também com apoio do Instituto Nacional de Ciência e Tecnologia sobre Comportamento, Cognição e Ensino, ao qual o primeiro e o terceiro autores são afiliados (processos $\mathrm{CNPq}$ 573972/2008-7 e FAPESP 2008/57705-8). Julio de Rose é bolsista de produtividade em pesquisa do CNPq. 


\section{A importância da leitura e o problema da alfabetização no Brasil}

Ser alfabetizado traz muitas vantagens tanto para o indivíduo quanto para a comunidade. Segundo Skinner (1957/1992), o grupo social também se beneficia quando possui mais um membro alfabetizado e, por isso, provê as consequências que estabelecem e mantêm o comportamento de ler (p. 66). Greer (2002) elaborou uma lista de comportamentos necessários ao sucesso individual e à contribuição social relevante no presente milênio, na qual o ler fluente, somado a uma gama variada de interesses de leitura, ocupa o primeiro lugar (p. 116). A leitura possibilita a ampliação do vocabulário e a aquisição de conhecimentos em geral (Bloomfield, 1942a/1970; Greer \& Ross, 2008, p. 216; Melzi \& Schick, 2013; Skinner, $1957 / 1992$, p. 67). O texto escrito suplanta as dimensões de tempo e espaço e através dele os sentidos do leitor são estendidos. O ler tem ainda as funções de entretenimento, lazer (Greer \& Ross, 2008, p. 19; Reis, 2009) e permite ao indivíduo governar seu próprio comportamento através da mediação do texto (Skinner, 1957/1992, p. 69), por exemplo, na solução de problemas complexos (Greer \& Ross, 2008, p. 20). O ler, certamente, é fundamental à vida cotidiana e ao sucesso acadêmico (Cagliari, 1997, p. 149; Greer, 2002, p. 119; Reis, 2009).

Como o aprendizado da leitura (e escrita) é tão importante, a efetividade do ensinar a ler torna-se uma tarefa particularmente desafiadora, sobretudo nos países em desenvolvimento como o Brasil. De acordo com a Pesquisa Nacional por Amostra de Domicílios (PNAD) realizada pelo Instituto Brasileiro de Geografia e Estatística (IBGE, 2015), em 2012 a taxa de analfabetismo da população brasileira era $8,7 \%$ e caiu para $8,5 \%$ em 2013. Apesar desta pequena redução, continua existindo um grande contingente de pessoas com 15 anos de idade ou mais, aproximadamente 13 milhões, (auto)declaradas inaptas a ler e a escrever um bilhete simples.

O desempenho dos estudantes em avaliações nacionais da educação brasileira, como o Sistema Nacional de Avaliação da Educação Básica (SAEB), também ilustra o problema do analfabetismo. Esta avaliação, bianual, realizada pelo Instituto Nacional de Estudos e Pesquisas Educacionais Anísio Teixeira, em $2003^{1}$, contou com uma amostra de 3.812.179 crianças do quarto ano do ensino fundamental (INEP, 2006). A média do desempenho das crianças nas avaliações de língua portuguesa foi de 169,4 pontos, quando o esperado seria um mínimo de 200 pontos. Além disto, $55,4 \%$ dos participantes da amostra apresentaram desempenho muito crítico ou crítico (significando, por exemplo, a impossibilidade de responder aos itens da prova ou ler frases simples e curtas) também nas avaliações de língua portuguesa.

Os problemas da educação no Brasil, como os elevados índices de analfabetismo, são bem conhecidos. Neste contexto, ações que possam contribuir para erradicar o analfabetismo constituem-se em importantes metas ético-políticas.

O presente trabalho consiste numa análise do método do ensino de leitura elaborado pelo eminente linguista Leonard Bloomfield, apresentado em "Let's Read" (Bloomfield \& C. L. Barhnart, 1961), feita à luz de pressupostos, processos e princípios analítico-comportamentais, buscando identificar convergências e complementaridades, assim como apontar dessemelhanças entre essas perspectivas.

\section{A importância de Bloomfield para a Linguística e sua influência sobre Skinner}

Leonard Bloomfield (1887-1949) foi um dos mais importantes linguistas do século XX, tendo influenciado tanto a linguística americana quanto a europeia (Fought, 1995, Koerner, 2003; Robins, 1997, pp. 237-238.). Ele é um dos formuladores da linguística estrutural, e seu ensino está no coração da linguística contemporânea (Hockett, 1984; Matthews, 1992/1999, pp. 139, 149). De acordo com Robins (1997, p. 244), a partir dos anos 1940, a maior parte da teoria e da prática linguística representa uma continuação do ou uma reação ao ensinamento de Bloomfield, em diferentes direções.

1 Este foi o relatório mais atual encontrado na página eletrônica do INEP (http://www.publicacoes.inep.gov.br/portal/ subcategoria/4) de acordo com os indicadores: publicações institucionais; avaliação da educação básica, apesar das avaliações serem bianuais e, consequentemente, haver avaliações mais recentes. 
Suas contribuições abarcam várias áreas e possuem diferentes propósitos, tais como as áreas de linguística geral, a descrição de línguas, a linguística histórica e comparativa, pesquisas em linguagem e metodologia científica, elaboração de métodos de ensino para leitura e língua estrangeira. Seu livro Language (1933/1961) é altamente apreciado (ver, por exemplo, Barsky, 2011, p. 39, 288; Bolling, 1935/1970; Coseriu, 1986, p. 149; Edgerton, 1933/1970; Howatt, 2002; Kroesch, 1933/1970; Lepschy, 1982, pp. 84-85; Sturtevant, 1934/1970), sendo considerado por alguns como o mais importante livro de linguística geral já escrito.

Bloomfield era um behaviorista e faz uma série de referências ao behaviorismo em suas obras (ver, por exemplo, Bloomfield, 1926/1970; 1927/1970; 1930/1970; 1931/1970; 1932/1970; 1933/1961, pp. $512,515 ; 1935 / 1970 ; 1936 / 1970 ; 1939 ; 1942 b / 1970)$. Ele foi um cientista fisicalista, combateu o mentalismo com veemência, e defendeu um método puramente empírico e indutivo na ciência em geral e em linguística especificamente. Em decorrência dessa perspectiva, sua descrição linguística se dirigia às formas manifestas da língua, concebendo-as como a expressão da estrutura linguística, sem buscar supostas atividades mentais sob estas formas (Fought, 1995). Bloomfield dedicou-se à análise fonológica e à gramática formal, com ênfase em morfologia. Sua exigência era trabalhar com fenômenos observáveis publicamente, os produtos da fala e da escrita. Seus elementos básicos de descrição da língua são o morfema, a menor unidade que tem significado, e o fonema, a menor unidade que não tem significado (Bloomfield, 1933/1961, pp. 158-161). Coerente com sua concepção fisicalista da linguagem, para ele, os enunciados são inteiramente constituído de morfemas - por sua vez constituídos de fonemas - e de seus arranjos gramaticais (Bloomfield, 1933/1961, pp. 158-169.).

A influência de Bloomfield sobre Skinner tem sido apontada, em maior ou menor grau, em uma série de trabalhos (e.g., Joseph, Love, \& Taylor, 2001, p. 110; McLeish \& Martin, 1975; Moxley, 1997). Ela ocorreu tanto em temas vastos, como concepção de ciência e método científico, refletindo-se no estudo do comportamento operante em geral, quanto em temas relacionados especificamente ao comportamento verbal, como a concepção fisicalista de sig- nificado, de ato de fala, de comunidade verbal e das funções da linguagem, a aceitação do fonema e do morfema como unidades de análise da fala, o uso do modelo da analogia para tratar da criatividade linguística e, mais importante do que tudo, a própria definição de Skinner de comportamento verbal (Matos \& Passos, 2006, 2010; Passos \& Matos, 2007; Passos, 2007a, Passos, 2007b).

\section{Breve história da elaboração de "Let's Read"}

Na década de 1920, motivado por ensinar seus filhos a ler, Bloomfield elaborou 72 listas de palavras (Hall Jr., 1990, pp. 35-36), a primeira versão de seu método de ensino de leitura de que se tem conhecimento. As listas de palavras consistiam em 231 páginas, com algumas frases para leitura de texto conectado, e apenas quatro páginas contendo palavras polissílabas (C. A. Barnhart, 2013). Segundo C. A. Barnhart (2013), nestas listas as palavras já se encontravam organizadas de acordo com: (a) a regularidade das correspondências entre grafema ${ }^{2}$ e fonema ${ }^{3}$; b) a frequência de ocorrência na escrita da língua inglesa, e c) o contraste entre pares de palavras impressas diferindo por uma (nas lições iniciais) ou por poucas (em lições mais avançadas) letras.

Com o objetivo de transformar as 72 listas de palavras em um método de ensino de leitura adequado para publicação, Bloomfield associou-se ao editor C. L. Barnhart e, em 1939, havia completado o manuscrito "Children's Reading," que tornou-se a base para a elaboração do livro que finalmente veio a ser publicado em 1961, "Let's Read" (Bloomfield \& C. L. Barnhart, 1961). “Children's Reading” possuía 461 páginas divididas em seis seções e, comparado às 72 listas originais de palavras, tinha mais sentenças e histórias criativas para a prática de leitura, elaboradas dentro dos limites impostos pela sequência de apresentação das relações grafema-fonema que

2 Grafemas são letras e outros símbolos gráficos como os diacríticos, os ideogramas como os números, e os sinais de pontuação usados na escrita (Câmara Jr., 2002, p. 128).

3 Fonemas são as menores unidades distintivas da fala (Bloomfield, 1933/1961, p. 79). 
melhor explorasse a regularidade dessas relações e introduzisse as irregularidades de maneira gradativa e planejada (C. A. Barnhart, 2013).

"Children's Reading" era um livro texto para ser manejado pelas crianças, mas na forma final que tomou em "Let's Read", transformou-se em um livro experimental publicado por uma universidade e manejável, principalmente, pelo professor. Tal reformulação e publicação ocorreram após o falecimento de Bloomfield, em 1949.

"Let's Read" tem 465 páginas divididas nas mesmas seis partes já encontradas em “Children's Reading" e contém aproximadamente 5.000 palavras escolhidas entre as mais frequentes em textos escritos na língua inglesa ${ }^{4}$ (C. L. Barnhart, 1961; C. A. Barnhart, 2013), o dobro do número de palavras que havia em "Children's Reading." Mais importante do que tudo, "Let's Read" preservou o principal eixo norteador do método de Bloomfield, o ensino de leitura baseado na regularidade das relações grafema-fonema e na sistemática introdução dos desvios da escrita da língua inglesa em relação ao princípio alfabético.

Finalmente, em 2010, "Let's Read," um dos livros mais antigos e populares publicados pela Wayne State University Press (C. A. Barnhart, 2013), ganhou uma versão revisada e atualizada por C. A. Barnhart e R. K. Barnhart (2010).

\section{Bloomfield: Concepção de leitura e método preconizado para seu ensino}

\section{Concepção de leitura em Bloomfield}

O tipo de escrita da língua está no cerne da concepção de leitura e do método preconizado para seu ensino, na perspectiva de Bloomfield. O inglês, assim como o português, tem escrita alfabética, regida pela correspondência, unidade a unidade, entre os fonemas e as letras (ou, de forma mais abrangente, grafemas) que os representam (Bloomfield, 1961). $\mathrm{Na}$ escrita alfabética, idealmente, cada letra deve re-

\footnotetext{
4 É possível que Bloomfield tenha utilizado a frequência relativa das palavras no inglês escrito encontrada em "A Teacher's Word Book" (Thorndike, 1931, citado por Bloomfield, 1933/1961, pp. 517, 542).
}

presentar um só fonema e, vice-versa, um fonema deve estar sempre representado por essa mesma letra. Os sistemas de escrita alfabética, entretanto, variam no grau de precisão desta correspondência, e a língua inglesa é considerada uma língua de escrita alfabética das mais imperfeitas (Bloomfield, 1961).

De acordo com a concepção de leitura de Bloomfield (1961), há duas tarefas a serem executadas pelo aprendiz: A primeira consiste em "obter os sons a partir da página escrita ou impressa" (pp. 31-32) e a segunda em "entender o significado desses sons" (p. 32). Segundo Bloomfield (1961), para "ler a escrita alfabética uma pessoa deve ter um hábito ${ }^{[5]}$, arraigado de produzir os sons de uma língua quando ela vê as marcas escritas que convencionalmente representam os fonemas"6 (p. 26, colchetes acrescentados). Responder adequadamente à correspondência entre grafemas e fonemas, e fazê-lo com fluência (com facilidade, rapidamente), é fundamental para que a compreensão ("pegar o conteúdo" expresso no texto), o objetivo final da leitura, se realize (Bloomfield, 1961).

A compreensão da leitura ocorre quando a criança ouve a si mesma emitindo os sons da fala correspondentes ao texto impresso (Bloomfield, 1961). No início da aprendizagem, a tarefa primordial de associar os grafemas aos fonemas correspondentes requer esforços significativos por parte da criança (é difícil de ser realizada), de modo que não deixa espaço para que ela ouça o que está lendo e, consequentemente, responda com compreensão ao texto impresso (Bloomfield, 1961). Para compreender o texto impresso a criança depende ainda de suas outras experiências como ouvinte e falante da língua (Bloomfield, 1961), tais como ter ouvido

5 Colchetes acrescentados. O mecanismo de formação de hábitos, nos moldes do condicionamento clássico, é empregado por Bloomfield para explicar a aprendizagem dos repertórios de falante, ouvinte, leitura e escrita (Passos, 2004, p. 72). Bloomfield utilizou o modelo de explicação do comportamento adotado pelos behavioristas de sua época, o condicionamento clássico. Os estudos sobre comportamento operante tinham apenas começado na década de 1930 quando Bloomfield, que era um behaviorista (Bloomfield, 1933/1961, p. 33), estava escrevendo seu método de alfabetização.

6 Todas as traduções dos textos em inglês que aparecem em citações neste texto foram realizadas pelos autores do presente artigo. 
histórias, ter-se comportado como ouvinte e falante diante dos nomes dos objetos e eventos do mundo, e ter respondido com conteúdo e forma apropriados a perguntas ouvidas. No início do ensino de leitura, a compreensão pode ser incentivada nas ocasiões em que o professor lê para a criança e, ouvindo a história, ela compreende o texto. Em uma etapa mais avançada, quando a criança lê com fluência as palavras do texto, ela pode compreendê-lo por si mesma (Bloomfield, 1961). Parte da solução para o problema das crianças que falham em compreender textos escritos envolve ensinar melhor as correspondências entre letras e sons da fala; outra parte envolve promover as condições para que a criança tenha as experiências com a língua que subsidiam tal compreensão (Bloomfield, 1961).

Bloomfield elaborou um método para o ensino de leitura em língua inglesa, mas os princípios norteadores do método podem ser empregados para o ensino de leitura em qualquer língua cuja escrita seja alfabética (Passos \& Matos, 2007).

\section{Método de ensino de leitura Bloomfieldiano ${ }^{7}$}

Características gerais do método. Objetiva-se estabelecer no aprendiz o comportamento de pronunciar determinado(s) fonema(s) diante de determinada letra ou conjunto de letras (Bloomfield, 1961), com acurácia, fluência (Bloomfield \& C. L. Barnhart, 1961, pp. 58-59, 126, 206, 286) e compreensão. A organização do material busca ainda facilitar o aprendizado da leitura e prevenir erros, uma vez que o hábito da leitura é fortalecido pelo "prazer do acerto"

7 A grande maioria dos exemplos de texto impresso, palavras, frases e sentenças em inglês, foi extraída de "Let's Read" (Bloomfield \& C. L. Barnhart, 1961). Em algumas ocasiões não indicaremos as páginas em que aparecem as palavras isoladas para não comprometer o fluxo do texto, mas há um índice em "Let's Read" (pp. 433-465) que indica as páginas onde elas podem ser encontradas. Os exemplos são fornecidos em inglês porque este é o idioma no qual o método foi elaborado. Para facilitar a compreensão, forneceremos alguns exemplos em português, embora o método ainda não tenha sido adaptado para este idioma. Adicionalmente, o leitor que achar necessário, pode utilizar o endereço eletrônico a seguir para obter a transcrição fonética das palavras em inglês: <http:// www.photransedit.com/online/text2phonetics.aspx $>$.
(Bloomfield, 1961) e enfraquecido pelo erro decorrente da introdução precoce de irregularidades na correspondência letra-fonema (Bloomfield, 1961). Neste método, a leitura é ensinada antes da escrita.

A criança precisa apresentar os seguintes comportamentos antes que possa iniciar este programa de ensino de leitura: (a) ser ouvinte e falante nativa ou fluente da língua em que aprenderá a ler; (b) ser capaz de seguir estímulos visuais na direção esquerda para a direita e (c) de distinguir e nomear as letras do alfabeto (Bloomfield, 1942a/1970), identificando-as como unidades discretas. Tendo estabelecido ou garantido a presença destes três pré-requisitos, o método de ensino de leitura pode ser iniciado.

\section{Composição dos materiais de ensino.}

Grau de regularidade das relações grafema-fonema. A relação entre a palavra escrita e a fala é a base para a análise linguística que vai selecionar as palavras cuja leitura deve ser ensinada e a sequência em que elas devem aparecer nas lições. Essa análise distingue escritas regulares, que respeitam rigorosamente o princípio alfabético (a cada unidade fonêmica corresponde uma única e mesma letra), de escritas não regulares, que se afastam deste princípio em maior ou menor grau ${ }^{8}$ (Bloomfield \& C. L. Barnhart, 1961, pp. 57-59). Na elaboração do método, Bloomfield define, para cada letra do alfabeto, a relação com um determinado fonema que ele vai considerar como regular. Outras ocorrências serão consideradas não regulares. Assim, por exemplo, são consideradas regulares as seguintes correspondências: $a$ como em cat, $i$ como em pin, $u$ como em cut, $c$ como em cat e $g$ como em get, enquanto $a$ como em date, $g$ como em gem e $c$ como em cent e scene são consideradas relações irregulares (Bloomfield \& C. L. Barnhart, 1961, pp. 57, 81, $87,290,357,376)$.

As relações não regulares são classificadas como semirregulares ou irregulares. Quando uma relação letra-fonema não regular aparece em várias palavras num mesmo contexto de letras comum a estas

8 Como as relações letra-fonema são convencionais, isto é, não há relação natural entre o estímulo visual da letra e o som da fala que ela representa, não cabe falar em relações inerentemente regulares, semirregulares ou irregulares. 
palavras, estas relações são consideradas semirregulares, casos em que o desvio em relação ao princípio alfabético pode ser descrito por uma regra ${ }^{9}$ (Bloomfield \& C. L. Barnhart, 1961, pp. 206-207; 284-285). Por exemplo, a letra a seguida por consoante e letra $e$ final como ate, fate, cake, cave, sale representa não a relação letra-fonema definida como regular ( $a$ como em cat), mas uma outra relação, $a$ como bait (com valor sonoro de ai; Bloomfield \& C. L. Barnhart, 1961, pp. 206-207, 284-285, 290). Depois de ser ensinado a ler muitas palavras com esse mesmo padrão, é presumível que o aprendiz seja capaz de ler uma nova palavra em que a letra $a$ apareça com este valor sonoro considerado semirregular, como fake ou save, desde que ele já tenha aprendido as relações letra-fonema das outras letras destas palavras, é claro (p. 290).

Relações irregulares são aquelas em que a correspondência entre letras (ou sequências de letras) e fonemas difere da correspondência estabelecida como regular e não atende aos critérios para classificação como semirregular, porque o valor sonoro que se afasta do princípio alfabético se verifica em um número menor de palavras (caso da letra $k$ não pronunciada como em knit, quando a correspondência definida como regular é a que ocorre em kit) ou porque muitas letras na palavra representam sons diferentes dos que foram estabelecidos como regulares, como seria o caso das palavras nature, impatient e example (Bloomfield \& C. L. Barnhart, 1961, pp. 206-207; 284-285; 359-361; 415-420).

A classificação das relações letra-fonema em regulares, semirregulares e irregulares estabelece o mais importante critério de escolha das palavras cuja leitura será ensinada e da ordem de seu ensino: primeiro serão ensinadas as que apresentam apenas relações regulares, depois são introduzidas palavras que apresentam relações semirregulares e, por último, as que apresentam relações mais irregulares (Bloomfield, 1942a/1970; 1961; Bloomfield \& C. L. Barnhart, 1961, pp. 57-430). Esta classificação visa, como já dissemos, promover o responder correto em função da regularidade das correspondências letra-fonema (ou de sua padronização) na apresen-

9 Note-se, entretanto, que as regras nunca são enunciadas para a criança e ela não é solicitada a enunciar a regra (Bloomfield \& C. L. Barnhart, 1961, pp. 206-207, 284-285). tação das palavras impressas e, consequentemente, eliminar ou reduzir erros (Bloomfield, 1942a/1970; 1961; Bloomfield \& C. L. Barnhart, 1961, p. 206).

Sílabas sem sentido são parte do programa de ensino e também são usadas como teste do domínio das correspondências letra-fonema que as compõem, desde que sejam formadas de acordo com as possibilidades de combinação dos fonemas naquela língua (Bloomfield, 1961; Bloomfield \& C. L. Barnhart, 1961, pp. 57-59).

Unidades de ensino. As unidades básicas de ensino são palavras impressas. Inicialmente, elas são do tipo CVC (consoante ${ }^{10}$-vogal-consoante, e.g., man, bat, bit) e VC (vogal-consoante, e.g., an, at, it). As palavras das primeiras 36 lições diferem umas das outras por apenas uma letra, cuja posição no interior da palavra é sistematicamente alterada. As palavras são contrastadas entre si, dentro de cada lição, pela letra inicial (e.g., bat, cat, fat, at); em lições sucessivas pela letra final (e.g., bat, bad, bag) e, paralelamente, por grupos formados pela letra vogal intermediária (e.g., bat, bit, but, bet; pan, pin, pun, pen; tap, tip, top; Bloomfield \& Barhnart, C.L., 1961, pp. 57-121).

Progressivamente, palavras impressas maiores são acrescentadas (e.g., sled, slid; desk, dusk; lamp, clamp; shrink, shrank), atingindo palavras tão longas quanto Colorado e December (Bloomfield \& C. L. Barnhart, 1961, pp. 127, 138, 144, 149, 320, 362). Palavras impressas são agrupadas em sentenças, bem curtas inicialmente, como por exemplo, "Dan had a cat" e "A rat hid in a bin" (Bloomfield \& C. L. Barnhart, 1961, pp. 68, 71). Com o progredir das lições, estas pequenas sentenças formam pequenos parágrafos, depois pequenas histórias, até se chegar a histórias de algumas páginas.

Note-se que não se trata de uma progressão absolutamente linear: há palavras menores que são ensinadas só depois que muitas palavras bem maiores já o foram. O tamanho da palavra é apenas um dos critérios de seleção do material, e ele interage com o importante critério exposto anteriormente, $\mathrm{o}$ grau de regularidade das relações grafema-fonema.

10 Neste artigo, por consoantes e vogais estamo-nos referindo a letras, unidades da escrita, e não a fonemas, unidades fonológicas. 
A sequência de ensino. "Let's Read" (Bloomfield \& C. L. Barnhart, 1961) é dividido em seis partes: Parte I: Primeiras leituras, Parte II: Leitura fácil, Parte III: Mais leitura fácil, Parte IV: As palavras irregulares mais comuns, Parte V: As escritas irregulares de sons de vogais mais comuns, e Parte VI: As escritas irregulares de sons de consoantes mais comuns.

Segundo Bloomfield e C. L. Barnhart (1961), "O trabalho nas lições 1-36 é o fundamento da leitura da criança e, talvez, a parte mais importante de toda a sua educação formal” (p. 57). A Parte I é composta por estas 36 lições. Somente palavras com correspondências grafema-fonema regulares são apresentadas neste estágio como bat, cat, fat; bit, fit, hit; bun, fun, gun; bug, dug, hug; bet, get, jet; cot, dot, got (Bloomfield \& C. L. Barnhart, 1961, pp. 60-95). Trata-se de palavras monossílabas em que as vogais escritas representam os sons vogais curtos (short vowels; C. A. Barnhart, 2013). Todas as relações grafema-fonema definidas como regulares são ensinadas nesta etapa. As letras $x$ e $q$ são ensinadas apenas na Parte II e palavras contendo letras "silenciosas" como knit e gnat (Bloomfield, 1942a/1970) aparecem apenas em estágios ainda mais avançados.

Embora a pronúncia do artigo $a$ não represente uma relação definida como regular (porque nele a letra $a$ é pronunciada como em fake e não como em cat), a leitura desta palavra é ensinada nesta etapa por permitir a introdução de texto conectado como em "A man ran a tan van. ... A fat cat ran at a fat rat" (Bloomfield, 1942a/1970; Bloomfield \& C. L. Barnhart, 1961, pp. 57, 60-61).

A Parte II é composta por 34 lições contendo palavras com correspondências grafema-fonema regulares e semirregulares. A principal novidade da Parte II é o ensino das sequências de consoantes. Utilizam-se: (a) palavras com duas ou mais consoantes sucessivas que mantêm a correspondência grafema-fonema definida como regular (milk e split); (b) s plural e 's sufixo indicador de pronome possessivo, como em caps e cat's, respectivamente; (c) sequências de duas ou três consoantes, por exemplo, ng (sing, ring), sh (shot, fish), th (thin, tenth), tch (catch, match); (d) palavras com consoantes duplicadas, como well e egg, cuja pronúncia é equivalente à pronúncia da consoante definida na Parte
I como regular; (e) qu (como em quit) e $x$ (como em box). Introduz-se também a palavra de escrita irregular the (Bloomfield \& C. L. Barnhart, 1961, pp. 125-164) para avançar na leitura de texto conectado como "A man had a rat. The man got a cat. The cat sat in the sun. It did not get the rat. The man got a rat trap..." (p. 135).

A Parte III é composta por 25 lições contendo palavras com duas vogais sucessivas como ee (see) e ea (eat), uma vogal seguida por $y$ ou $w$ (oy como em boy e aw como em saw), duas vogais sucessivas seguidas de $r$ (air como em chair, oar como board), e vogal $e$ silenciosa ao final como em have e give (Bloomfield \& C. L. Barnhart, 1961, pp. 167-201). Também são introduzidas mais palavras com duas sílabas, principalmente palavras compostas (e.g., mailbox, mailman, p. 180). Introduzem-se histórias com título e alguns poucos parágrafos (até seis), contendo apenas relações grafema-fonema ensinadas até aquele ponto.

Uma vez que a criança chegou até esta etapa, supõe-se que esteja respondendo de modo acurado às relações grafema-fonema regulares e semirregulares.

A Parte IV é composta por 53 lições contendo as palavras mais comuns com uma letra ou sequência de letras cuja correspondência com o(s) fonema(s) é definida como irregular. Por exemplo, th como em than e with (a correspondência letra-fonema definida como regular é a que ocorre em thin, tenth), e $s$ como em is, his, has, as (cuja correspondência letra-fonema definida como regular ocorre em sat e sit); palavras com sufixos como es ou 's correspondendo à pronúncia de ez: dishes, wishes e Gus's, Max's; palavras de três e quatro sílabas como banana e arithmetic; as palavras to, of, was; alguns pronomes como $I$, you; a contração n't (didn't), além de outras (Bloomfield \& C. L. Barnhart, 1961, pp. 205-280).

A Parte V é composta por 52 lições com palavras com as escritas irregulares mais comuns para os sons das vogais. Apresentam-se, em diferentes lições, palavras em que a letra $a$ corresponde a diferentes fonemas como em safe, car e ask, por exemplo. Adicionalmente, são introduzidas palavras impressas com as seguintes correspondências: ea como em steak e como em head (em listas separadas; ea como em eat foi a forma definida como "regular"); are, ear, ere, como em care, bear, there (soando como air em 
chair); $i$ como em bite ( $i$ como em bit representa a correspondência regular); além de outras correspondências grafema-fonema irregulares (Bloomfield \& C. L. Barnhart, 1961, pp. 283-353).

A Parte VI é composta por 45 lições com palavras contendo a escrita irregular mais comum para os sons das consoantes e também algumas escritas irregulares de vogais que ocorrem em grupos de pouquíssimas palavras. Nesta parte introduzem-se palavras com a letra $c$ como em center; $g$ como em gem; letras silenciosas como $k, g$, $c$, respectivamente como em knee, gnat, scene, e a combinação de letras silenciosas gh como em caught e high e também gh como em rough. Introduzem-se ainda: ie como em sieve; $i$ como em police; ie como em piece e $x$ como em exact (Bloomfield \& C. L. Barnhart, 1961, pp. 357-430). Estes são apenas alguns poucos exemplos das formas apresentadas nesta parte, que exige várias lições porque cada uma delas vai agrupar palavras que apresentem um mesmo tipo de irregularidade. A estratégia de Bloomfield para o ensino da leitura de palavras com escrita irregular é extrair da língua escrita algum padrão, pelo agrupamento de palavras que contêm o mesmo tipo de irregularidade, como, por exemplo, no ensino da leitura de palavras com $b$ silencioso: lamb, limb, dumb, numb, crumb, thumb, climb, comb, debt, doubt (Bloomfield \& C. L. Barnhart, 1961, p. 371; Lição 209).

O aspecto crítico desta seleção de palavras escritas e de sua ordem de apresentação é a oportunidade que oferece de ensinar inicialmente uma única, e sempre a mesma, resposta vocal diante de uma letra, até se esgotarem as relações regulares letra-fonema que precisam ser ensinadas. Desse modo, reduz-se a probabilidade de a criança cometer erros decorrentes do ensino de mais de uma resposta à mesma unidade do estímulo no estágio inicial do aprendizado de leitura. Segue-se então o ensino de outros valores sonoros correspondentes às mesmas letras, isto é, das relações letra-fonema semirregulares e, por último, o das irregulares. Em todos os casos, supõe-se que a apresentação de uma série de palavras em que se repete uma letra ou conjunto de letras que devem evocar a emissão de um mesmo fonema ou sucessão de fonemas facilita a aprendizagem da relação letra-fonema.

Procedimentos de ensino. O procedimento reco- mendado por Bloomfield e C. L. Barnhart (1961) baseia-se numa extrapolação, para o ensino de leitura, do teste de comutação, que utiliza pares mínimos de palavras para identificar os fonemas de uma língua (Tabachnick, 1962), transformando-o num instrumento pedagógico (C. A. Barnhart, 2013). Inicialmente, as palavras cuja leitura é ensinada diferem umas das outras por apenas uma letra/um fonema, de modo que a relação entre a letra e o fonema que estabelece o contraste com as outras palavras de um mesmo conjunto de pares mínimos torna-se a única base para a distinção entre estas palavras escritas, como ocorre, por exemplo, no conjunto de pares mínimos cat, bat, sat, fat, hat, mat, rat, em que as palavras se diferenciam umas das outras apenas pela primeira letra/ primeiro fonema. Outros conjuntos de pares mínimos usados no método se diferenciam apenas pela segunda ou pela última letra, como exemplificado no próximo parágrafo.

O professor aponta para uma palavra impressa e solicita à criança que a soletre; ele lê a palavra para ela, e pede que a criança a leia. Primeiramente, apresenta-se uma palavra por vez e, posteriormente, pares de palavras que diferem por uma única letra. Por exemplo, o professor apresenta a palavra can e pede que a criança a soletre. Em seguida diz: "Essa palavra é can. Leia!"11 E a criança lê: “can." Em seguida, o professor faz o mesmo com a palavra impressa fan e, em seguida, pode apresentar o par de palavras impressas can e fan, solicitando sua leitura. Depois que os diversos pares de palavras impressas são facilmente lidos pela criança, utilizam-se sequências maiores de palavras diferentes entre si por apenas uma letra (sempre variando a posição da palavra no par ou na sequência). Novas palavras impressas são combinadas, inicialmente, com palavras de uma mesma lição e depois entre lições, por exemplo, bat-cat, cat-fat, bad-bat, mad-mat, bit-bat, bat-but, but-bit.

Seguindo a lógica de progresso gradativo, o número de palavras ensinadas em cada sessão também pode ser aumentado. Procede-se deste modo até que a criança seja capaz (a) de ler com acurácia e fluência a palavra apontada pelo professor e

11 Neste trabalho estamos utilizando aspas para indicar letra, sílaba, palavra ou sentença falada. 
(b) de apontar para a palavra impressa quando o professor a pronuncia. O domínio completo das relações grafema-fonema ensinadas em cada palavra é critério essencial para avançar no programa (Bloomfield, 1961; Bloomfield \& C. L. Barnhart, 1961, pp. 57-59).

Sendo uma tarefa que requer esforços consideráveis por parte do aprendiz, recomenda-se que as sessões de ensino sejam de curta duração. Recomenda-se revisar a leitura das palavras ensinadas na sessão anterior, antes de iniciar uma nova sessão (Bloomfield, 1961).

\section{Skinner: Concepção de leitura e método de ensino}

\section{Concepção de leitura em Skinner}

Em “Verbal Behavior," Skinner (1957/1992) adotou o termo comportamento verbal para tratar dos fenômenos comumente relacionados à linguagem e indicou como o ambiente social modela e mantém o comportamento verbal do indivíduo (p. 2). O comportamento verbal é comportamento operante, estabelecido e mantido em função das consequências que produz. Entretanto, trata-se de um caso especial de comportamento operante, porque a apresentação (ou remoção) dos estímulos consequentes que o estabelecem e mantêm não decorre diretamente da ação do indivíduo sobre o ambiente não humano, mas decorre da mediação de um ouvinte especialmente treinado em práticas específicas de uma comunidade verbal (Skinner, 1957/1992, pp. 225-226). A apresentação das consequências pelo ouvinte depende de o comportamento do falante apresentar as convenções vigentes na comunidade verbal, principalmente o conjunto de convenções que os linguistas denominam língua (Passos, 2012).

Skinner (1957/1992) utilizou o termo textual para se referir ao componente mais básico do comportamento de ler, o responder verbal vocal sob controle de estímulos textuais (textos escritos/impressos), em que há correspondência ponto a ponto entre as unidades do estímulo e as unidades da resposta $^{12}$ (pp. 65-66, 71, 128). Um exemplo de com-

12 Correspondência ponto a ponto ocorre quando o estímulo discriminativo e a resposta possuem dois ou mais componen- portamento textual é, diante da palavra impressa bala, pronunciar "bala."

A compreensão do texto lido ocorre, usualmente, num segundo momento, quando a fala produzida pelo textual evoca o comportamento de ouvinte no leitor, isto é, quando o falante ouve a si mesmo, e depende de outras experiências do leitor como ouvinte e falante da língua (de Rose, 2005; Skinner, 1957/1992, pp. 66, 169). Se o leitor não possui em seu repertório comportamental de ouvinte as respostas apropriadas aos operantes verbais que ouve e cujo registro foi feito no texto que está lendo (e supondo que o próprio texto não apresente os estímulos necessários ao seu estabelecimento), mesmo ouvindo a si mesmo não compreenderá o texto. Podemos inventar alguns exemplos para tentarmos nos colocar no lugar do leitor que é capaz de apresentar o textual correspondente ao texto escrito, mas não tem o repertório de ouvinte necessário para compreender o texto (Passos, 2011). Por exemplo, o leitor poderia apresentar o responder textual adequado à leitura da sentença Mesmo com a valiste iluminada, não se via o pafo e ainda assim não ser capaz de compreendê-la, por não ter aprendido previamente a se comportar como ouvinte dos tatos ${ }^{13}$ valiste e pafo, que, em nosso exemplo inventado, significariam, respectivamente, gruta e amuleto. Do mesmo modo, podem faltar-lhe experiências

tes e cada componente do estímulo controla um componente da resposta, na sequência apropriada (Peterson, 1978). A escrita alfabética pode ser imprecisa ao registrar os fonemas da língua (Skinner, 1957/1992, p. 65) e, consequentemente, comprometer a precisão da correspondência ponto a ponto entre o texto escrito/impresso e a resposta verbal vocal que ele deve evocar. Por exemplo, na língua portuguesa, observa-se correspondência ponto a ponto na leitura das palavras bala e mala. Por outro lado, não se observa correspondência ponto a ponto na leitura das palavras chato (composta por cinco letras diante das quais pronunciam-se quatro fonemas) e hoje (que possui uma letra $h$ silenciosa; Passos, 2003).

13 Tato é o operante verbal em que a forma das respostas está sob controle de estímulo discriminativo não verbal, os objetos e eventos do mundo. Tatos são estabelecidos e mantidos por reforçamento generalizado contingente a respostas de determinada forma consistentemente correlacionadas com um estímulo ou certa propriedade de estímulo (Skinner, 1957/1992, pp. 81-83). 
prévias com um autoclítico ${ }^{14}$ como o pronome átono $o$, no exemplo Eu o vi ontem, construção encontrada com frequência na língua escrita, mas muito mais raramente na língua falada. Não é difícil imaginar que muitas das nossas crianças talvez nunca tenham ouvido esta construção antes de encontrá-la em algum texto escrito na escola.

As duas principais explicações analítico-comportamentais para as dificuldades em leitura envolvem a ausência do repertório comportamental textual básico acurado e fluente (caso de uma dificuldade generalizada de leitura) ou a presença do comportamento textual não acompanhada de experiências relevantes como ouvinte e falante da língua (dificuldades pontuais que comprometem a compreensão do texto; Passos, 2011; Passos, 2003). Além dessas, outras dificuldades podem ainda envolver a ausência de repertórios pré-requisito como não seguir com os olhos da esquerda para a direita (de Rose, 2005), ou não ouvir a si mesmo (de Rose, 2005; Greer \& Ross, 2008, pp. 217-221; 229-233). Em muitos casos, essas dificuldades se combinam impossibilitando completamente a leitura. Em qualquer caso, destaca-se a análise das contingências de ensino e não a classificação ou rotulação do aprendiz (de Rose, 2005; Greer, 2002, p. 7) na explicação do problema.

\section{Como ensinar segundo Skinner}

Características gerais do ensino. Em "Verbal Behavior," Skinner (1957/1992) afirma que estabelecer um adequado controle de estímulos é o principal objetivo dos procedimentos utilizados no ensino do textual. Uma contingência de três termos descreve as relações funcionais entre estímulos e respostas características do controle de estímulos: um estímulo antecedente estabelece a ocasião na qual uma resposta de determinada forma em geral

14 O autoclítico é um operante verbal cuja ocorrência está condicionada à presença de outros operantes verbais (Skinner, 1957/1992, pp. 313, 330). O autoclítico articula de diversos modos (comentando, qualificando, organizando, selecionando e relacionando, por exemplo) esses outros operantes verbais (p. 312), inclusive outros autoclíticos (Passos, 2004, p. 171). Os autoclíticos correspondem, em muitos aspectos, àquilo que os linguistas estudam no contexto da gramática e sintaxe (Skinner, 1957/1992, p. 331). é reforçada (Skinner, 1957/1992, pp. 31, 53-54, 8183, 115; Vargas, 2013). As contingências educacionais de reforço estão especialmente voltadas para estabelecer um adequado controle de estímulos e para refinar a forma dos operantes verbais (Skinner, 1957/1992, pp. 84-86). No ensino do textual, tais contingências estabelecem novos controles de estímulos, possibilitando que a criança responda oralmente aos estímulos visuais das palavras escritas (de Rose, 2005).

O planejamento de contingências de reforçamento que favoreçam mudanças comportamentais no aprendiz, promovendo ou acelerando o aprendizado, constitui a base do ensinar (Skinner, 1968/2003, pp. 4-5, 64-65, 113, 150). Indivíduos aprendem sob muitas circunstâncias não planejadas mas, nestes casos, não se diz que houve educação ou ensino (Skinner, 1968/2003, pp. 5, 64-65). Para um bem-sucedido planejamento das condições de ensino, é preciso especificar nitidamente os comportamentos inicial e final do programa de ensino, os reforçadores disponíveis, e as formas de tornar estes últimos contingentes às repostas requeridas (Skinner, 1968/2003, pp. 19-20). Também é possível planejar contingências de ensino que promovam a aprendizagem indireta de relações entre estímulos e entre estímulos e respostas (de Rose, 2005; de Rose, de Souza, Rossito \& de Rose, 1989), ampliando-se desse modo os efeitos das contingências de ensino planejadas.

Comportamentos ensinados na escola ficam sob controle de reforçadores automáticos decorrentes do próprio responder (checar uma resposta e constatar que ela está correta, por exemplo), e o professor deve cuidar para que isso ocorra, mas, nos estágios iniciais do ensino, em geral, reforçadores condicionados generalizados como "Certo!" ou "Bom!" apresentados pelo educador são necessários (Skinner, 1968/2003, pp. 16, 20, 156-157).

\section{Composição dos materiais de um programa de} ensino. Uma programação de ensino estabelece contingências de três termos nas quais deve ocorrer reforçamento imediato das respostas corretas. Uma sequência muito cuidadosa de passos ensina novas respostas ao aprendiz, ou novo controle de estímulos sobre respostas já adquiridas (de Rose, 2005), de forma a que estas respostas sejam emitidas sem 
erros (ou com o mínimo de erros), aos estímulos apropriados, ao longo do programa, simultaneamente à manutenção das respostas já aprendidas, como resultado do reforçamento gerado pelo acerto. Desse modo, adicionalmente, previnem-se as potenciais consequências aversivas comumente associadas ao erro (Skinner, 1968/2003, pp. 20-21, 33). "Estar certo também significa progresso, e a estrutura física de um programa geralmente torna o progresso visível" (Skinner, 1968/2003, p. 157).

Uma parte fundamental da programação do ensino é a elaboração dos seus materiais ${ }^{15}$ (Skinner, $1968 / 2003$, pp. 20-21, 39). Os materiais de ensino devem ser apresentados numa sequência criteriosamente elaborada para que evoquem, com elevada probabilidade, o responder correto do aprendiz (Holland \& Pittsburgh Univ., 1976, p. 727; Sidman \& Stoddard, 1966). As etapas sucessivas devem seguir uma ordem presumivelmente efetiva em que comportamentos pré-requisitos são ensinados até serem dominados, antes que sejam demandados em etapas posteriores do programa de ensino (Sidman, 1985; Sidman, 2010; Skinner, 1968/2003, pp. 24, 34-35, 39, 48, 61, 220-221). Nunca se exige do aprendiz um responder para o qual não tenha sido adequadamente preparado, o que faz com que as respostas requeridas sejam emitidas com facilidade (Sidman, 2010; Skinner, 1968/2003, 34-35, $50-52,107)$, ou, dito de outra forma, sejam altamente previsíveis, mesmo que alguma estimulação suplementar, como "dar a entender," dar dicas, ou sugerir, seja necessária (Skinner, 1968/2003, pp. 37-39, 219). Note-se que o sucesso do responder resulta das contingências tríplices estabelecidas sistematicamente. Se os passos não são adequadamente dimensionados ou não estão efetivamente sequenciados, a facilidade de execução da instrução programada provavelmente fica comprometida (Skinner, 1968/2003, pp. 221-222). Desse modo, dificuldades no aprendizado são atribuídas aos procedimentos de ensino e não imputadas ao aluno ou ao meio em que vive, pois procedimentos de ensino apropriados permitem estender, até mesmo,

15 Cabe ressaltar que, em geral, Skinner (1968/2003) discute a programação de ensino e, consequentemente, a elaboração de seus materiais no contexto das máquinas de ensinar (por exemplo, pp. 21, 22-28, 29-53, 59-61). limitações impostas por condições orgânicas (de Rose, 2005).

\section{Unidades de ensino e aprendizagem do textual.}

A delimitação das menores unidades dos operantes textuais depende do tipo de escrita da língua: pictórica, hieroglífica, alfabética, etc., ou seja, do tipo de estímulo que deve adquirir controle sobre o responder (Skinner, 1957/1992, p. 65). Em línguas com escrita predominantemente alfabética como o português e o inglês, o nível fonético define o limite do menor operante textual que pode resultar do reforçamento de unidades textuais mais amplas contendo elementos idênticos (Skinner,1957/1992, pp. $62,67,116)$ ou do ensino direto da unidade isolada (Skinner,1957/1992, pp. 62, 116). Assim, por exemplo, diante dos estímulos textuais bala, cala, mala, uma criança poderia, além de responder textualmente sob controle das palavras inteiras ("bala," "cala," etc.), apresentar o operante textual sob controle de partes destas palavras (por exemplo, de $b$, ala, $b a, l a, l, a, c)$. Embora a maioria das respostas textuais a esses estímulos não ocorra isoladamente, tais componentes podem adquirir controle funcional independente sobre o responder do aprendiz .

Qualquer que seja o tamanho da unidade do estímulo a ser adotada no ensino do comportamento textual (letra, sílaba, palavra, frase ou sentença, por exemplo), o leitor habilidoso apresentará operantes textuais de tamanhos variados (Skinner, 1957/1992, pp. 67, 116). O responder adequado a estímulos textuais não familiares depende do controle adquirido pelas unidades mínimas sobre este responder (Skinner, 1957/1992, pp. 76-77, 116-117).

Skinner (1957/1992) reconhece a existência de um debate na área da educação a respeito do tamanho da unidade mais apropriada para o ensino de leitura, mas não opina a respeito. No contexto desta discussão, ele afirma que um repertório básico de unidades textuais ao nível da letra e do fonema surgem como resultado do reforçamento da leitura de unidades maiores, como, por exemplo, da palavra (p. 67). Skinner, entretanto, não explica como unidades menores são aprendidas a partir do reforçamento de unidades maiores, nem indica trabalhos experimentais que suportem sua afirmação.

Estudos posteriores, em análise do comportamento, vieram a dar apoio parcial a esta afirma- 
ção de Skinner. Por exemplo, de Rose, de Souza e Hanna, (1996) e Mueller, Olmi e Saunders (2000) ensinaram, principalmente, relações condicionais entre palavras ditadas como modelo e figuras/fotografias e palavras impressas como comparações e verificaram a leitura tanto das palavras impressas integrantes do procedimento de ensino quanto a leitura de palavras não diretamente ensinadas, formadas pela recombinação de unidades de estímulo menores do que a palavra (componentes das palavras ensinadas: sílabas no primeiro estudo, e letra inicial e duas letras seguintes [onset e rime] em palavras CVC no segundo). Em um outro estudo, Matos, Avanzi, e McIlvane (2006) utilizaram palavras (ditadas e impressas) como estímulos nos procedimentos de ensino, mas incluíram no programa de ensino de leitura (dentre outros) procedimentos envolvendo o ensino direto de relações condicionais em que sílabas ditadas eram estímulos modelo e sílabas impressas eram parte do estímulo de comparação (parte da palavra impressa ${ }^{16}$, parte da palavra a ser construída ${ }^{17}$ ) definido como correto e obtiveram, igualmente, resultados muito positivos na leitura das palavras integrantes dos procedimentos de ensino e daquelas compostas pela recombinação de sílabas das palavras utilizadas no ensino.

Procedimentos de ensino. Em "Science and Human Behavior," Skinner (1953/2014) se referiu brevemente ao ensino do comportamento de ler (textual) como um processo de discriminação operante:

Quando lemos em voz alta, respondemos a uma série de estímulos visuais com uma série

16 Por exemplo, se a sílaba ditada fosse " $b o$," a palavra utilizada como estímulo de comparação correto conteria essa sílaba, dependendo da fase do ensino, ora como primeira sílaba em palavras CVCV, como em boca (posição inicial), ora como segunda sílaba como em lobo (posição final).

17 Por exemplo, nas tarefas de emparelhamento ao modelo com reposta construída (CRMTS-ID) uma palavra era apresentada como modelo na forma impressa e a criança devia compor uma palavra igual utilizando blocos de madeira contendo sílabas impressas como estímulos de comparação. Nas tarefas de emparelhamento arbitrário com repostas construída (CRMTS-ARB) uma palavra era ditada como modelo e blocos contendo sílabas impressas eram os estímulos de comparação a partir dos quais a criança deveria compor a palavra que ouviu. de respostas vocais correspondentes. A contingência de três termos é evidente ao ensinar uma criança a ler, quando uma determinada resposta é reforçada com "certo" ou "errado" de acordo com a presença ou ausência do estímulo visual apropriado. (Skinner, 1953/2014, p. 109)

O procedimento de reforçamento diferencial permite estabelecer o controle de estímulos, incluindo o texto impresso/escrito, sobre o responder textual (Skinner, 1953/2014, pp. 93, 95-98; Skinner, 1957/1992, pp. 66, 69, 89, 115). Considerando o ensino do estímulo textual bala, procede-se da seguinte forma: Mostra-se a palavra impressa bala e quando a resposta verbal vocal "bala" é emitida segue-se o reforçador “Certo!" ou "Bom!” Por outro lado, mostra-se, por exemplo, a palavra impressa mala, na presença da qual dizer "mala" e não "bala" é seguido por "Certo!" Quando dizer "bala" passa a ocorrer na presença de bala, mas não de mala (e de outras palavras impressas), então há controle de estímulos. Neste ponto a palavra impressa bala tornou-se um estímulo discriminativo para dizer "bala" e é parte das variáveis que controlam esta forma de responder. O mesmo procedimento poderia ser aplicado às demais palavras escritas, o que resultaria no aprendizado do operante textual por ensino direto.

Um aspecto importante neste ensino é a adoção de reforçadores condicionados generalizados que tornam o responder verbal relativamente independente de estados de privação e estimulação aversiva que $\mathrm{o}$ aprendiz possa experimentar ${ }^{18}$, favorecendo $\mathrm{o}$ estabelecimento do controle de estímulos (Skinner, 1957/1992, pp. 54-55, 83-84, 209), como o “Certo!" já citado (Skinner,1957/1992, pp. 54, 84, 185).

O reforçamento automático do responder textual pode ocorrer nas ocasiões em que a criança que está aprendendo a ler e já possui algum repertório textual, ouve a si mesma, e a fala produzida pelo texto lhe soa familiar (de Rose, 2005; Skinner, 1957/1992, pp. 66; 68-69; Skinner, 1968/2003, pp. $157,213)$. Por exemplo, ocorre reforçamento auto-

18 Skinner (1957/1992) afirma que outra forma de alcançar este mesmo efeito é utilizar muitos diferentes reforçadores para reforçar uma resposta na presença de um estímulo (pp. $53,83-84)$. 
mático quando uma criança lê uma palavra como fivela e a reconhece como existente: " $A h$, é aquilo onde passa o cinto" (o que, em geral, indica que a leitura está correta), o que torna a emissão da resposta "fivela" na presença da palavra fivela mais provável e prontamente emitida em ocasiões futuras. Depois que a criança já adquiriu alguns operantes textuais, o reforçamento automático decorrente de ouvir a si mesma emitindo textuais possibilita igualmente a autocorreção (de Rose, 2005; Skinner, 1957/1992, pp. 69; 164). Este tipo de reforçamento, entretanto, não é característico dos estágios iniciais do aprendizado de leitura, nos quais reforçadores extrínsecos, frequentemente, são necessários (de Rose, 2005; Skinner, 1968/2003, p. 16). As contingências de reforço devem ser planejadas de modo que os reforçadores extrínsecos sejam reduzidos e os reforçadores intrínsecos gradativamente adquiram controle sobre a leitura (de Rose, 2005; Skinner, $1968 / 2003$, pp. 85-86). As respostas textuais (assim como ocorre com os outros operantes) não são reforçadas todas as vezes em que são emitidas (Skinner,1957/1992, p. 89), mas o reforçamento diferencial é uma condição para estabelecimento dos operantes verbais e sua manutenção, e, portanto, deve ser parte do procedimento de ensino.

\section{O método comportamental de ensino de leitura de Bloomfield}

O método de ensino de leitura de Bloomfield é compatível com uma análise operante da leitura e com procedimentos de ensino utilizados em análise do comportamento. Além disso, os elementos envolvidos no método possibilitam experimentação que pode resultar em seu aperfeiçoamento, assim como à sua adequação a diferentes necessidades de diferentes aprendizes. Apresentamos a seguir uma breve comparação entre as concepções de leitura e de seu ensino em Bloomfield e em Skinner, que permite ressaltar a semelhança de suas abordagens.

Ambos, Bloomfield e Skinner, definem o repertório mais fundamental da leitura em termos compatíveis com as ciências naturais: ver o estímulo impresso, o texto, e emitir as respostas verbais vocais correspondentes, que Bloomfield (1961) chamou de hábito alfabético e Skinner (1957/1992) de textual (pp. 65-66).
Bloomfield (1961) entende a leitura com compreensão como uma segunda tarefa decorrente do acurado e fluente hábito alfabético. Também para Skinner (1957/1992), a leitura com compreensão ocorre num segundo momento, quando o leitor ouve a si mesmo emitindo os fonemas correspondentes às letras e pode então reagir à sua fala nos moldes instituídos pela comunidade verbal (pp. 66, $169,277,314)^{19}$. Para que responda nestes moldes, o indivíduo precisa ter as respostas de ouvinte em seu repertório comportamental, assim como outros operantes verbais (Skinner, 1957/1992, pp. 66; 169, 190; Skinner, 1968/2003, pp. 157, 213; de Rose, 2005), fenômenos aos quais podemos inferir que Bloomfield (1961) se referiu ao falar de "outras experiências com a língua" (p. 32).

Quando as crianças apresentam problemas em leitura, segundo Bloomfield (1961), o primeiro passo seria ensinar adequadamente as correspondências entre os grafemas e fonemas. Se ainda assim o problema persiste, então a classificação e descrição dos operantes verbais realizada por Skinner (1957/1992) podem ser vistas como um complemento à abordagem bloomfieldiana, por permitir identificar quais operantes verbais necessitam ser ensinados e como fazê-lo. Uma análise funcional determina os operantes ausentes do repertório comportamental da criança e o planejamento de contingências de ensino cria as condições para que estes repertórios sejam estabelecidos. Neste contexto, situações de fracasso no aprendizado envolvem, prioritariamente, a análise dos procedimentos de ensino, considerando-se também a história prévia do indivíduo, assim como possibilidades e limites biológicos (de Rose, 2005).

O método de ensino de leitura de Bloomfield objetiva estabelecer as correspondências entre letras e fonemas especificando cuidadosamente os comportamentos inicial e final, assim como os vários estágios entre eles, tal como requerido por uma análise comportamental para a programação de contingências de ensino efetivas. Os repertórios comportamentais pré-requisitos são igualmente definidos.

19 Em “Technology of Teaching” Skinner (1968/2003) fornece uma série de exemplos que indicam que ele supõe que a compreensão do que é lido ocorre num segundo momento (ver por exemplo, pp. 157, 202, 213). 
A soletração da palavra antes de sua leitura é um desses pré-requisitos que facilita o controle de estímulos de cada unidade do estímulo textual sobre uma resposta verbal vocal, evitando o estabelecimento de topografias de controle de estímulo impróprias (de Rose, 2004; Holland \& Pittsburgh Univ., 1976), como, por exemplo, ler a palavra sob controle apenas de sua primeira ou última letra. Segundo de Rose (2005), ensinar à criança a identificar propriedades relevantes dos estímulos textuais, como acreditamos ser o caso da identificação das letras como unidades discretas nas palavras inteiras, é um aspecto crucial no ensino de leitura. Adicionalmente, de Rose (2005) afirma que jogos e brincadeiras podem ser recursos pedagógicos significativos no estabelecimento de discriminações das propriedades relevantes dos estímulos, recursos estes que não foram abordados nem por Bloomfield nem por Skinner (até onde é de nosso conhecimento), mas que podem ser considerados complementos interessantes, por exemplo, no ensino dos nomes das letras às crianças ou, de outro pré-requisito, do seguir com o olhar da esquerda para a direita.

O método bloomfieldiano apresenta palavras inteiras para a criança, tal como ela vai efetivamente encontrar nos textos escritos. Ele o faz, entretanto, de maneira tão engenhosa de forma a ensinar as correspondências letra-fonema relevantes sem que seja preciso quebrar a palavra em sílabas e letras isoladas, o que seria artificial, porque apenas as palavras, não as sílabas e letras, aparecem isoladamente nos textos escritos. O ensino dessa correspondência é possível porque o material de ensino é organizado muito sistematicamente a partir de princípios linguísticos apropriados (o princípio alfabético e a classificação das palavras escritas de acordo com o grau de regularidade em relação a esse princípio), permitindo o estabelecimento do controle de estímulos sobre a emissão dos fonemas correspondentes em função da propriedade relevante destes estímulos (as letras e sua sequência na palavra) sem exigir que a criança incorra na artificialidade de pronunciar os sons da fala isoladamente diante das letras. ${ }^{20}$

20 Alguns métodos fônicos tentam estabelecer a correspondência letra-fonema ensinando a pronunciar os fonemas
De modo geral, quando procedimentos de ensino produzem desempenhos precisos ou com pouco erro, falamos em aprendizagem sem erros (Melo, Hanna \& Carmo, 2014). Alguns pesquisadores (e.g., Sidman, 2010; Sidman \& Stoddard, 1966; Stoddard, de Rose, \& McIlvane, 1986; Terrace, 1963a, 1963b) salientaram que erros não são inerentes ao processo de aprendizagem e que eles indicam aspectos inadequados do planejamento do ensino e não da aprendizagem do aluno. Segundo estes autores, diante da ocorrência de erros, os procedimentos de ensino precisam ser analisados e reformulados. Em análise do comportamento, alguns procedimentos têm sido testados, avaliados e/ou aplicados na produção de aprendizagem sem erros, como é o caso, por exemplo, do esvanecimento e modelagem do estímulo (Holland \& Pittsburgh Univ. 1976; Iñesta, 1972/1980; Terrace, 1963a, 1963b), e da exclusão (de Rose et al., 1989; Melchiori, de Souza, \& de Rose, 1992), e caberia analisar em que medida o método de Bloomfield é compatível com estes procedimentos.

Skinner (1968/2003, pp. 16, 20-22, 32-33, 37-39, $48,60-61,107,156-157,221-224)$ indicou alguns requisitos para a programação do ensino que contribuem para a promoção da aprendizagem sem erros. O método de ensino elaborado por Bloomfield atende aos princípios característicos da instrução programada que se seguem:

- Define nitidamente o comportamento final (ver características gerais do método).

- Exige do aprendiz a emissão de uma reposta ativa e pública (em etapas iniciais do aprendizado; Skinner, 1968/2003, pp. 124-125) que no contexto do ensino de leitura, é falar em voz alta os fonemas na sequência em que eles ocorrem nas palavras, ou seja, diante da palavra impressa can dizer "can," diante da palavra impressa fan dizer "fan."

- Apresenta uma progressão sistemática e organizada dos passos com o objetivo de reduzir a ocorrência de erros e promover o reforçamento

correspondentes às letras isoladamente e se deparam com a dificuldade de fazer as crianças combinarem os sons da fala para formar a palavra falada (Ehri, Nunes, Stahl, \& Willows, 2001/2002). 
automático pelo acerto, permitindo simultaneamente o avanço no programa e a manutenção dos repertórios já adquiridos.

- A progressão nas diversas dimensões como a regularidade-irregularidade das correspondências grafema-fonema e o tamanho das palavras e dos textos; a alternância ordenada da posição das letras nas palavras de treino, garantindo-se que formem combinações possíveis na língua, mesmo no caso de palavras sem sentido; o dispositivo dos pares mínimos e, em geral, o agrupamento das palavras por padrão físico semelhante, compõem um conjunto que, articulado, tende a ser efetivo (considerando-se que sejam parte das tríplices contingências de ensino).

- Ensina pré-requisitos comportamentais (no início e ao longo do programa) antes que sejam demandados, como, por exemplo, (a) a discriminação e nomeação de todas as letras do alfabeto antes de começar as lições de leitura das palavras, (b) a requisição da resposta de discriminação de cada letra da palavra antes de lê-la (dizer os nomes das letras que compõem a palavra), (c) muitas lições iniciais com palavras monossílabas, o que propicia o ensino de muitas relações letra-fonema que irão constituir palavras maiores, cuja leitura é ensinada em lições posteriores. Assim, ao se ensinar a leitura de uma palavra maior, evita-se que muitas relações letra-fonema novas sejam ensinadas ao mesmo tempo.

- Não requer do aprendiz respostas para as quais ele não tenha sido devidamente preparado, como exemplificado pela apresentação gradativa e sistemática dos desvios da escrita em relação ao princípio alfabético (semirregularidades e irregularidades) e pelo seu ensino somente após o aprendiz ter adquirido competência e fluência nas relações letra-fonema regulares. No início, evita-se o ensino de respostas incompatíveis capazes de gerar dúvida e erro, como uma letra correspondendo às vezes a um fonema e outras vezes a outro (como $c$ em cat e cent; ou uma letra correspondendo a nenhum fonema, como $g$ em gnat; ou ainda duas letras correspondendo a um único fonema, como $l l$ em bell). Estes são alguns exemplos dos desvios da escrita em relação ao princípio alfabético em que um mesmo estímulo discriminativo (as letras) evoca mais de uma resposta, donde podem surgir dificuldades, erros e dúvidas no aprendizado de leitura. Ao apresentar as palavras em grupos que favorecem o controle condicional sobre o valor sonoro de cada letra exercido pelas demais letras da palavra, o método de Bloomfield minimiza a confusão acarretada pela violação do princípio alfabético que ocorre na escrita, como na sequência lamb, limb, dumb, numb, comb, debt, doubt (Bloomfield \& C. L. Barnhart, 1961, p. 371).

- Utiliza estimulação suplementar, por exemplo, dicas ecoicas, fornecidas quando o professor apresenta o modelo de leitura das palavras ao aluno (conforme descrevemos na seção procedimento de ensino), que serão gradativamente esvanecidas à medida em que o desempenho da criança demonstrar que elas não são mais necessárias.

Falta ao método bloomfieldiano a explicitação de reforçadores generalizados que podem compor as contingências de três termos no ensino de leitura. Bloomfield (1961) referiu-se muito enfaticamente à importância do acerto do aprendiz durante o aprendizado de leitura, insistindo em que o método deveria conduzir o aprendiz a acertos no responder, produtores de "ganho de poder", ou fortalecedores "da firmeza dos hábitos" aprendidos. Bloomfield (1942a/1970, 1961) não sugere outros potenciais reforçadores no ensino de leitura. Skinner (1968/2003 pp. 16, 20, 156-157) caracterizou o acerto, o estar certo, como importante elemento das contingências de reforço na programação de ensino eficaz, podendo funcionar como evento que produz auto-reforçamento de respostas. Entretanto, ele afirmou que nos estágios muito iniciais de ensino algum reforçamento extrínseco, como o "Certo!" do professor, pode ser necessário. Neste caso, é preciso planejar contingências de ensino que promovam a transição de reforçadores extrínsecos à leitura, para reforçadores intrínsecos (de Rose, 2005; Skinner, 1968/2003, pp. 85-86). Este é um pequeno exemplo de como a combinação de técnicas de análise do comportamento podem ser usadas em conjunto com o método de ensino de Bloomfield para tornar mais eficaz o ensino de leitura. 
A aplicação do método bloomfieldiano é compatível com o procedimento básico de reforçamento diferencial para produzir controle de estímulos, mas permanece a questão da definição de outros reforçadores e sua utilização de maneira explícita, planejada e contingente ao responder do aprendiz. Além disso, os procedimentos de ensino e processos envolvidos precisam ser mais bem compreendidos, e estudos experimentais com o método de Bloomfield e os procedimentos de ensino de análise do comportamento podem vir a produzir um ensino mais eficaz, mais preciso, mais rápido, com menos repetição.

Adicionalmente, cabe enfatizar que tanto Bloomfield (1942a/1970, 1961) quanto Skinner (1968/2003) apontaram a importância da interação entre certas áreas do conhecimento, ao que vamos chamar trabalho interdisciplinar, no processo de ensinar (leitura para Bloomfield e ensino em geral para Skinner). Bloomfield (1961) defendeu o trabalho conjunto do linguista e do pedagogo no ensino de leitura. Ao linguista, conhecedor da língua, caberia definir o conteúdo a ser ensinado; ao pedagogo, conhecedor dos métodos de ensino, caberia definir as técnicas (tecnologias) para ensinar ( $p$. 19). Segundo Bloomfield, "Somente se escolhermos nosso material de acordo com a natureza da escrita em inglês, o procedimento que prepararmos para a classe com todo cuidado irá produzir os resultados apropriados" (Bloomfield, 1942a/1970, p. 395). As principais consequências de proceder assim seriam o aprendizado de leitura em um tempo menor, com maior precisão e melhor compreensão do conteúdo.

Segundo Skinner (1968/2003), a programação de ensino exigiria tanto o conhecimento técnico do especialista numa determinada área, quanto o conhecimento dos aspectos práticos da realidade do ensinar (o que se pode ensinar com o tempo que se tem, por exemplo), além da tecnologia comportamental (pp. 206, 224). Articular estes conhecimentos permitiria realizar um planejamento de contingências de reforçamento que, deliberada e intencionalmente, modificam o comportamento do aprendiz, evitam a utilização do controle aversivo (que produz efeitos colaterais indesejáveis) e maximizam os acertos, possibilitando ao indivíduo aprender melhor e mais facilmente (Skinner, $1968 / 2003$, pp. 5, 64-65, 95-102).
É interessante que Bloomfield tenha defendido a importância de se elaborar um método de ensino de leitura que aumentasse as chances de o aprendiz emitir respostas corretas e reduzisse as chances de que cometesse erros (um análogo à aprendizagem sem erros da perspectiva analítico-comportamental), num método de ensino que começou a ser escrito nos anos de 1920. Essa defesa aparece, por exemplo, na crítica que faz aos métodos fônicos que procuram ensinar a criança a pronunciar os fonemas correspondente às letras isoladamente:

... Pessoas que falam inglês não estão acostumadas a fazer este tipo de barulho [pronunciar isoladamente certos sons da fala diante de certas letras]. O som ( $t$ ) [por exemplo] não ocorre isoladamente quando se fala inglês; nem o som $(t)$ seguido pelo som de uma vogal obscura. Se insistirmos em fazer a criança desempenhar proezas incomuns com seus órgãos vocais, estamos condenados a confundir a resposta dela diante dos sinais impressos. Em qualquer língua a maioria dos fonemas não ocorre sozinha em falas isoladas, e mesmo a maioria das sucessões de fonemas que se pode teoricamente conceber nunca é enunciada. Não devemos complicar nossa tarefa adotando demandas não usuais sobre o poder da criança de pronunciar. (Bloomfield, 1942a/1970, p. 389; colchetes acrescentados)

A defesa de métodos de ensino de leitura que promovam a emissão de respostas corretas pelo aprendiz, também aparece quando Bloomfield aponta para a necessidade do cuidadoso planejamento da introdução dos distintos valores sonoros que as letras podem representar em diferentes palavras:

... se próximo ao início do ensino, apresentarmos as palavras get e gem, não podemos esperar que a criança desenvolva qualquer reposta fixa e fluente diante da letra $g$. Se falarmos com ela sobre os sons 'forte' e 'fraco' da letra $g$, nós a confundimos ainda mais. As irregularidades da nossa escrita - ou seja, seus desvios do princípio alfabético - demandam manuseio cuidadoso para que não confundam a criança e 
não atrasem sua aquisição do hábito alfabético (Bloomfield, 1942a/1970, p. 390).

Nas duas citações abaixo, Bloomfield ressalta a importância do ensino de relações letra-fonema consistentes, evitando o aparecimento de erros e da dúvida no aluno:

... Não precisamos temer usar palavras desconectadas ou mesmo sílabas sem sentido, e acima de tudo, não devemos ... aborrecer os hábitos da criança fracamente formados pela apresentação de irregularidades da escrita para as quais ela não está preparada. Exercícios puramente formais que seriam cansativos para um adulto, não o são para uma criança, desde que ela veja a si mesma ganhando em poder. Nos estágios iniciais de leitura uma sílaba sem sentido como nim conferirá prazer à criança que se acha apta a lê-la, enquanto no mesmo estágio uma palavra de escrita irregular tal como gem, mesmo que introduzida numa estória, irá desencorajar a criança e atrasar a firmeza de suas reações. (Bloomfield, 1942a/1970, p. 392)

O trabalho nesse primeiro estágio [do ensino de leitura, em que a correspondência letra-fonema em praticamente todas as palavras ensinadas é absolutamente a definida como regular] é de suma importância e deve ser continuado até que os alunos estejam bem fortemente treinados (Bloomfield, 1942a/1970, p. 394; colchetes acrescentados).

Bloomfield foi pioneiro na defesa de uma forma de ensino que minimize erros, assim como o foi ao defender o ensino das correspondências letra-fonema como elemento crítico no ensino de leitura. A prioridade do ensino dessas correspondências é hoje amplamente aceita, embora raramente os autores mencionem Bloomfield (Cagliari, 1997, p. 150; Ehri, Nunes, Stahl, \& Willows, 2001/2002; Morais, 1994/1996, p. 268; National Reading Panel [NRP], 2000). Que outras de suas contribuições podem ser reveladas por uma análise mais detalhada de seu método de ensino de leitura à luz da análise comportamental? Os evidentes indícios de compatibilidade e complementaridade entre o método de ensino de leitura de Bloomfield (1942a/1970, 1961) e a análise comportamental de Skinner (1957/1992; 1968/2003) sugerem a importância de se explorar melhor estas relações. Até onde sabemos, a implementação do método, como um programa completo, não foi ainda aliada, de modo planejado, a princípios e procedimentos de análise comportamental. Além disso, até onde é de nosso conhecimento, ele não foi adaptado para o ensino de leitura em outras línguas, incluindo a língua portuguesa.

A adaptação do método à língua portuguesa e sua combinação com princípios e procedimentos de instrução programada seriam muito bem-vindas, prometendo produzir um método de ensino com grande potencial para participar da solução do problema dos altos índices de analfabetismo e das dificuldades educacionais decorrentes dele. Esta adaptação exige o trabalho dos linguistas, capazes de aplicar os princípios que norteiam o método às características específicas da escrita e da fala em língua portuguesa, com a identificação das relações grafema-fonema que precisam ser ensinadas, em que sequência, com o uso de quais palavras e textos conectados.

O trabalho dos analistas do comportamento permitiria programar as contingências eficazes ao estabelecimento destas relações, com o ensino dos pré-requisitos comportamentais, a apresentação planejada de estímulos e reforçadores, a gradação adequada do ensino do material, o uso de técnicas como fornecimento de pistas, critérios para seu esvanecimento, avaliação permanente do que já foi e não foi aprendido, procedimentos de correção, experimentação com diferentes possibilidades de ensino apontadas pelo material, com vários tipos diferentes de aprendizes (diferenças de idade e/ou desenvolvimento, ensino do português como língua estrangeira), etc.

Esperamos que este programa de colaboração entre as duas áreas possa concretizar-se num futuro (muito) próximo. 


\section{Referências}

Barnhart, C. L. (1961). The story of the Bloomfield system. Em L. Bloomfield, \& C. L Barnhart. Let's Read: a Linguistic Approach (pp. 9-17). Detroit: Wayne State University Press.

Barnhart, C. A. (2013). A little-known aspect of Leonard Bloomfield's linguistics: the story of let's read (1961). Historiographia Linguistica, 40, 433-476.

Barnhart, C. A. \& Barnhart, R. K. (2010). Let's Read: a Linguistic Approach. Detroit: Wayne State University Press.

Barsky, R. F. (2011). Zellig Harris: from American linguistics to socialist Zionism. Cambridge: MIT Press.

Bloomfield, L. (1970). A set of postulates for the science of language. Em C. F. Hockett (Ed.), A Leonard Bloomfield anthology (pp. 128138). Bloomington: Indiana University Press. (Reimpresso de Language, 2, pp. 153-164, 1926.)

Bloomfield, L. (1970). On recent work in general linguistics. Em C. F. Hockett (Ed.), A Leonard Bloomfield anthology (pp. 173-190). Bloomington: Indiana University Press. (Reimpresso de Modern Philology, 25, pp. 211230, 1927.)

Bloomfield, L. (1970). Linguistics as a science. Em C. F. Hockett (Ed.), A Leonard Bloomfield anthology (pp. 227-230). Bloomington: Indiana University Press. (Reimpresso de Studies in Philology, 27, pp. 553-557, 1930.)

Bloomfield, L. (1970). Albert Paul Weiss. Em C. F. Hockett (Ed.), A Leonard Bloomfield anthology (pp. 237-239). Bloomington: Indiana University Press. (Reimpresso de Language, 7, pp. 219-221, 1931.)

Bloomfield, L. (1970). Lautgesetz und Analogie, by Eduard Hermann. [Review]. Em C. F. Hockett (Ed.), A Leonard Bloomfield anthology (pp. 240-251). Bloomington: Indiana University Press. (Reimpresso de Language, 8, pp. 220-232, 1932.)

Bloomfield, L. (1961). Language. New York: Holt, Rinehart and Winston. (Trabalho original publicado em 1933.)
Bloomfield, L. (1970). Linguistic aspects of science. Em C. F. Hockett (Ed.), A Leonard Bloomfield anthology (pp. 307-321). Bloomington: Indiana University Press. (Reimpresso de Philosophy of Science, 2, pp. 499-517, 1935.)

Bloomfield, L. (1970). Language or ideas? Em C. F. Hockett (Ed.), A Leonard Bloomfield anthology (pp. 322-328). Bloomington: Indiana University Press. (Reimpresso de Language, 12, pp. 89-95, 1936.)

Bloomfield, L. (1939). Linguistic Aspects of Science. International Encyclopedia of Unified Science, Vol. 1 (4). Chicago: University of Chicago Press. Bloomfield, L. (1970). Linguistics and reading. Em C. F. Hockett (Ed.) (1970). A Leonard Bloomfield anthology (pp. 384-395). Bloomington: Indiana University Press. (Reimpresso de Elementary English Review, 19, pp. 125-130, 183-186; 1942a.)

Bloomfield, L. (1970). Philosophical Aspects of Language. Em C. F. Hockett (Ed.), A Leonard Bloomfield anthology (pp. 396-399). Bloomington: Indiana University Press. (Reimpresso de Studies in the history of culture: The disciplines of humanities, pp. 173-177. Menasha: George Banta, 1942b.)

Bloomfield, L. (1961). Teaching children to read. Em L. Bloomfield, \& C. L. Barnhart. Let's read: a linguistic approach. (pp. 19-42) Detroit: Wayne State University Press.

Bloomfield, L., \& Barnhart, C. L. (1961). Let's read: a linguistic approach. Detroit: Wayne State University Press.

Bolling, G. M. (1970). Language, by L. Bloomfield. [Review]. Em C. F. Hockett (Ed.), A Leonard Bloomfield anthology (pp. 277-278). Bloomington: Indiana University Press. (Reimpresso de Language, 11, pp. 251-252, 1935.)

Cagliari, L. C. (1997). Alfabetização e linguística. São Paulo: Scipione.

Câmara Jr., J. M. (2002). Dicionário de linguística e gramática (24a edição). Petrópolis: Vozes.

Coseriu, E. (1986). Lecciones de linguística general. Madrid: Gredos.

de Rose, J. C. (2004) Além da resposta correta: Controle de estímulo e o raciocínio do aluno. Em M. M. C. Hubner, \& M. Marinotti. (Orgs.). 
Análise do comportamento para a educação: contribuições recentes (pp. 103-113). Santo André: ESETEC.

de Rose, J.C. (2005). Análise comportamental da aprendizagem de leitura e escrita. Revista Brasileira de Análise do Comportamento, 1, 2950.

de Rose J. C., de Souza D. G, \& Hanna E. S. (1996). Teaching reading and spelling: Exclusion and stimulus equivalence. Journal of Applied Behavior Analysis, 29, 451-469.

de Rose, J. C., de Souza, D. G., Rossito, A. L., \& Rose, T. M. S. (1989). Aquisição de leitura após história de fracasso escolar: equivalência de estímulos e generalização. Psicologia: Teoria e Pesquisa, 5, 325-346.

Edgerton, F. (1970). Language, by L. Bloomfield. [Review]. Em C. F. Hockett (Ed.), A Leonard Bloomfield anthology (pp. 258-260). Bloomington: Indiana University Press. (Reimpresso de Journal of the American Oriental Society, 53, 295-297, 1933.)

Ehri, L. C., Nunes, S. R., Stahl, S. A., \& Willows, D. M. (2002). Systematic phonics instruction helps students learn to read: evidence from the National Reading Panel's meta-analysis. Journal of Direct Instruction, 2, 121-166. (Reimpresso de Review of Educational Research, 71, 393-447, 2001.)

Fought, J. (1995). American Structuralism. Em E. F. K. Koerner, \& R. E. Asher (Eds.), Concise History of the Language Sciences: from the Sumerians to the cognitivists (pp. 295-306). New York: Pergamon Press.

Greer, R. D. (2002). Designing teaching strategies: an applied behavior analysis systems approach. San Diego: Elsevier Academic Press.

Greer, R. D., \& Ross, D. E. (2008). Verbal behavior analysis: inducing and expanding complex communication in children with severe language delays. Boston: Allyn \& Bacon.

Hall Jr., R. A. (1990). A life for language: A biographical memoir of Leonard Bloomfield. Amsterdam: John Benjamins.

Hockett, C. F. (1984). Foreword. In L. Bloomfield (1933/1984), Language (pp. ix-xiv). Chicago: The University of Chicago Press.

Howatt, T. (2002). Introduction. Em K. Malmkjær
(Ed.), The linguistics encyclopedia (2nd. ed., pp. xxv-xli). New York: Routledge.

Holland, J. G., \& Pittsburgh Univinersity, P. A. (1976) Learning Research and Development Center. Analysis of Behavior in Reading Instruction. Retirado de: http://eric.ed.gov/?id=ED155625

Iñesta, R. E. (1980). Técnicas de modificação do comportamento: Aplicação ao atraso no desenvolvimento (D. P. Soares, Trad.). São Paulo, SP: EPU. (Original publicado em 1972.)

Instituto Brasileiro de Geografia e Estatísticas (2015). Taxa de analfabetismo das pessoas de 15 anos ou mais de idade, por sexo - Brasil 2007/2013. Retirado de http://brasilemsintese. ibge.gov.br/educacao/taxa-de-analfabetismo-das-pessoas-de-15-anos-ou-mais

Instituto Nacional de Estudos e Pesquisas Educacionais Anísio Teixeira (2006) Relatório Nacional Saeb 2003 (v.1). Brasília: Inep. Retirado de http://www.publicacoes.inep.gov. br/portal/download/449

Joseph, J. E., Love, N., \& Taylor, T. J. (2001). Landmarks in linguistic thought II: the Western tradition in the twentieth century. London: Routledge.

Koerner, E. F. K. (2003). Remarks on the origins of morphophonemics in American structuralist linguistics. Language \& Communication, 23,1-43.

Kroesch, S. (1970). Review de Language (1933), de L. Bloomfield. Em C. F. Hockett (Ed.), A Leonard Bloomfield anthology (pp. 260264). Bloomington: Indiana University Press. (Reimpresso de Journal of English and Germanic Philology, 32, 594-597, 1933.)

Lepschy, G. C. (1982). A survey of structural linguistics. London: Andre Deutsch.

Matos, M. A., Avanzi, A. L., \& McIlvane, W. J. (2006). Rudimentary reading repertoires via stimulus equivalence and recombination of minimal units. The Analysis of Verbal Behavior, 22, 3-19.

Matos, M. A., \& Passos, M. L. R. F. (2006). Linguistic sources of Skinner's Verbal Behavior. The Behavior Analyst, 29, 89-107.

Matos, M. A., \& Passos, M. L. R. F. (2010). Emergent verbal behavior and analogy: Skinnerian and linguistic approaches. The Behavior Analyst, $33,65-81$. 
Matthews, P. H. (1992). Bloomfield's morphology and its successors. Em J. Fought (Ed.). (1999). Leonard Bloomfield: critical assessments of leading linguists: Vol. 3. Phonology, morphology and languages (pp. 102-152). London: Routledge.

McLeish, J., \& Martin, J. (1975). Verbal behavior: a review and experimental analysis. The Journal of General Psychology, 93, 3-66.

Melchiori, L. E., Souza, D. G., \& Rose, J. C., (1992). Aprendizagem de leitura por meio de um procedimento de discriminação sem erros (exclusão): uma replicação com pré-escolares. Psicologia: Teoria e Pesquisa, 8, 101-11.

Melo, R. M., Hanna, E. S., \& Carmo, J. C. (2014). Ensino sem erro e aprendizagem de discriminação. Temas em Psicologia, 22, 207-222.

Melzi, G., \& Schick, A. R. (2013). Language and literacy in the school years. Em J. B. Gleason, \& N. B. Ratner (Orgs.) The development of language (8th. ed.). Boston: Pearson.

Morais, J. (1996). A arte de ler. (A. Lorencini, Trad.). São Paulo: Editora Unesp. (Trabalho original publicado em 1994.)

Moxley, R. A. (1997). Skinner: from essentialist to selectionist meaning. Behavior and Philosophy, 25, 95-119.

Mueller, M. M., Olmi, D. J., \& Saunders, K J. (2000). Recombinative generalization of within-syllable units in prereading children. Journal of Applied Behavior Analysis, 33, 515-531.

National Reading Panel. National Institute of Child Health and Human Development, National Institutes of Health. (2000) National Reading Panel: Teaching children to read: an evidence-based assessment of the scientific research literature on reading and its implications for reading instruction. Reports of the subgroups. Washington, D.C.. Retirado de: http://www. nichd.nih.gov/publications/pubs/nrp/documents/report.pdf

Passos, M. L. R. F. (2007a). Skinner's definition of verbal behavior and the arbitrariness of the linguistic signal. Temas em Psicologia, 15, 161-172.

Passos, M. L. R. F. (2007b). Bloomfield and Skinner: speech-community, functions of language, and scientific activity. The Journal of SpeechLanguage Pathology and Applied Behavior Analysis, 1(4)/2(1), 76-96.
Passos, M. L. R. F. (2003) Análise funcional do comportamento, linguística estrutural e alfabetização. DataGramaZero - Revista de Ciência da Informação, 4 (5).

Passos, M. L. R. F. (2004) Bloomfield e Skinner. Lingua e comportamento verbal. Rio de Janeiro: Nau editora.

Passos, M. L. R. F. (2011). O modelo de alfabetização de Leornard Bloomfield e a análise funcional do comportamento verbal: possíveis aplicações à língua portuguesa. II Simpósio do Instituto Nacional de Ciência e Tecnologia sobre Comportamento, Cognição e Ensino. São Carlos, $\mathrm{SP}$

Passos, M. L. R. F. (2012). B. F. Skinner: the writer and his definition of verbal behavior. The Behavior Analyst, 35, 115-26.

Passos, M. L. R. F., \& Matos, M. A. (2007). The influence of Bloomfield's linguistics on Skinner. The Behavior Analyst, 30, 133-151.

Peterson, N. M. L. (1978). An introduction to verbal behavior. Grand Rapids: Behavior Associates.

Reis, T. S. (2009). Avaliação da eficácia de um programa suplementar para o ensino de leitura e escrita aplicado em ambiente escolar (Dissertação de Mestrado). Universidade Federal de São Carlos, São Carlos.

Robins, R. H. (1997). A short history of linguistics (4th ed.). London: Longman.

Sidman, M. (1985). Aprendizagem-sem-erros e sua importância para o ensino do deficiente mental. Psicologia, 11, 1-15.

Sidman, M. (2010). Errorless learning and programmed Instruction: the myth of the learning curve. European Journal of Behavior Analysis, 12, 167-180.

Sidman, M., \& Stoddard, L. T. (1966). Programming perception and learning for retarded children. In N. R. Ellis (Ed.), International review of research in mental retardation (v. 2, pp. 151-208). New York: Academic Press.

Skinner, B. F. (2014). Science and human behavior. B. F. Skinner Foundation. (Trabalho original publicado em 1953.)

Skinner, B. F. (1992). Verbal behavior. Acton: Copley. (Trabalho Original Publicado em 1957.) 
Skinner, B. F. (2003). The technology of teaching. Massachusetts: Copley Publishing Group. (Trabalho original publicado em 1968.)

Stoddard, L. T., de Rose, J. C. C., \& Mcilvane, W. (1986). Observações curiosas acerca do desempenho deficiente após a ocorrência de erros. Psicologia, v. 12, n. 1, p. 1-18.

Sturtevant, E. H. (1970). Language, by L. Bloomfield. [Review]. Em C. F. Hockett (Ed.), A Leonard Bloomfield anthology (pp. 265266). Bloomington: Indiana University Press. (Reimpresso de The Classical Weekly, 27, 159160, 3/26/1934.)

Tabachnick, B. R. (1962). A linguist looks at reading: Leonard Bloomfield and the phonemic criterion. Elementary English, 39, 545-548.

Terrace, H. S. (1963a). Discrimination learning with and without "errors." Journal of the Experimental Analysis of Behavior, 1, 1-27.

Terrace, H. S. (1963b). Errorless transfer of a discrimination across two continua. Journal of the Experimental Analysis of Behavior, 6, 223-232.

Vargas, E. A. (2013). The Importance of Form in Skinner's Analysis of Verbal Behavior and a Further Step. The Analysis of Verbal Behavior, 29, 167-183.

Informações do Artigo

Histórico do artigo:

Submetido em: 23/06/2015

Primeira decisão editorial: 24/08/2015

Aceito em: 05/10/2015 